\title{
Evaluation of prescribing pattern and rationality of fixed dose combinations in patients of general medicine department
}

\author{
Nupuri Joshi ${ }^{1}$, Anvita Falke ${ }^{1}$, Sajin Saji ${ }^{1}$, Arundhati Diwan ${ }^{2}$, Asawari Raut ${ }^{1}{ }^{*}$
}

\author{
${ }^{1}$ Department of Clinical Pharmacy, Bharati Vidyapeeth Deemed to be University, Pune, Maharashtra, India \\ ${ }^{2}$ Department of Medicine, Bharati Hospital and Research Centre, Pune, Maharashtra, India
}

Received: 18 October 2019

Revised: 01 December 2019

Accepted: 03 December 2019

\section{*Correspondence:}

Dr. Asawari Raut,

Email: asawari.raut@gmail.com

Copyright: (C) the author(s), publisher and licensee Medip Academy. This is an open-access article distributed under the terms of the Creative Commons Attribution Non-Commercial License, which permits unrestricted non-commercial use, distribution, and reproduction in any medium, provided the original work is properly cited.

\begin{abstract}
Background: Fixed dose combinations are widely used in India, they are either irrational or prescribed irrationally. Moreover, the government has recently banned over 300 fixed dose combinations (FDCs) because of a lack of therapeutic justification. This study was conducted to study the prescribing pattern of FDCs in a tertiary care teaching hospital and to highlight the rationality of FDCs, and adverse drug reactions (ADRs) associated with them.

Methods: In the present prospective observational study, a total of 500 inpatients were evaluated for prescribing pattern, cost analysis, and adverse drug reactions (ADRs) of FDCs. The FDCs were assessed for their rationality. The ADRs and severity were assessed using the WHO causality scale, Hartwig severity scale respectively.

Results: Out of total 103 FDCs, 58 were approved, 86 were rational and 17 were irrational. 5 FDCs were banned and irrational. $48.54 \%$ of rational FDCs had rationality score from 7 to 9 . The most commonly prescribed FDCs belonged to the anatomic therapeutic and chemical class of respiratory system, followed by anti-infectives in younger age group

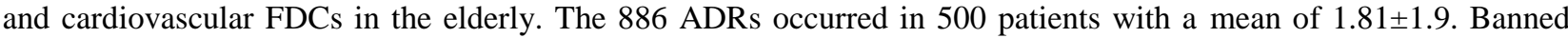
FDCs contributed to 76 ADRs. According to causality and severity assessment, most of the ADRs were possible $(62.53 \%)$ and mild $(70.77 \%)$ respectively.

Conclusions: Although FDCs were rational in most cases but banned FDCs were also prescribed. As these FDCs were associated with ADRs, monitoring of patients is necessary. Knowledge and attitude of healthcare professionals can be assessed through awareness programs.
\end{abstract}

Keywords: FDCs, ADRs, Rationality, Banned

\section{INTRODUCTION}

Fixed dose combination (FDC) is the combination of 2 or more active pharmaceutical ingredients (APIs) in a single dosage form designed to meet the requirements of the patient. It is an attempt to reduce the complexity of regimen in case of polypharmacy and enhance drug compliance; but they can cause interactions, adverse drug reactions (ADRs) or resistance (in case of antibiotics) when irrational or prescribed irrationally ultimately leading to increased healthcare cost. ${ }^{1,2}$ Not to forget, FDCs are being widely used in India and not all of them are rational. Irrational FDCs came in the market because companies take the license from State Licensing Authority (SLA) and SLA is under impression that FDC has been reviewed and necessary documents are checked and approved by the Central Licensing Authority (CLA), then SLA permits for import, manufacture, market or sale of FDC. 
The possible reason for a wide range of FDCs in the Indian market is marketing interest and the fact that developing new chemical entity is difficult for a pharmaceutical company than to develop and market the FDC or fierce competition between manufacturers resulting in the products which don't have necessary therapeutic justification, safety, and efficacy. ${ }^{3}$ While taking into account all the facts about FDCs, the Central Drugs Standard Control Organization had banned sales of 294 FDCs in 2007 but then companies and industry associations used legal means to push back government's order and now in 2018, once again the government has banned manufacture sale and distribution of over 300 FDCs due to lack of therapeutic justification. This study was conducted to evaluate the prescribing pattern, rationality of FDCs and ADRs caused by them if any in this tertiary care setting.

\section{METHODS}

A prospective observational study was carried out in the inpatient General Medicine Department of Bharati Hospital and Research Centre. A total of 500 patients were studied in 6 months (October 2018 to March 2019) for prescribing pattern of FDCs, their cost analysis and ADRs associated with them. The data was collected using a specially designed patient profile form and information regarding the presenting complaints, medical and medication history, medicines prescribed during hospitalization, laboratory investigations and daily notes were recorded to detect the possible ADRs. ADRs were assessed using the WHO causality scale and the Hartwig severity scale was used for assessment of severity of ADRs, the rationality of FDCs was assessed using a 7 point rationality assessment scale by Panda et al. ${ }^{4}$ The study included all the inpatients that have been prescribed with at least 1 FDC. But pediatric patients were excluded from the study because it's difficult to prescribe an FDC in these patients due to difficulty in dividing the dose. Nutraceuticals were also excluded from the study because of the difficulty of their assessment. The data was collected, entered and assessed using Microsoft Excel 2007 and the results were recorded using descriptive statistics along with pivot tables.

\section{RESULTS}

Out of 500 inpatients, 261 were males and 239 were females. Age distribution of patients revealed that maximum patients belong to the age group of 48 to 57 years followed by 18 to 27 years and lastly age group of more than 78 years with an average age of patient being $47.58 \pm 17.94$ years.

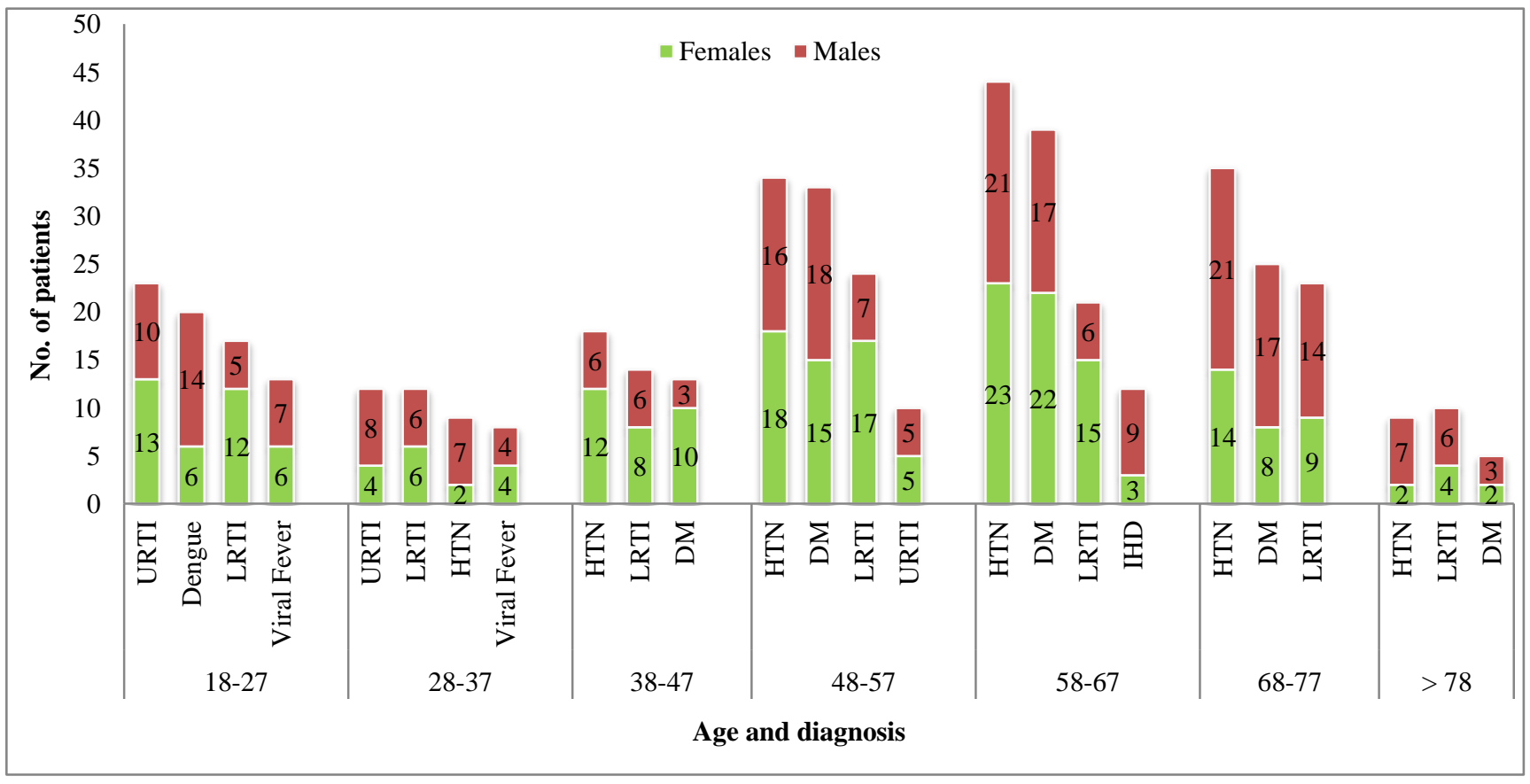

Figure 1: Disease wise distribution of patients.

URTI=upper respiratory infection, LRTI=lower respiratory tract infection, HTN=hypertension, DM= diabetes mellitus, IHD= ischemic heart disease.

A total of 307 drugs were prescribed to the patient with a mean of $7.47 \pm 2.66$ drugs per patient. Out of 307 drugs, $103(33.55 \%)$ were FDCs with the mean of $1.71 \pm 1.02$ FDCs per patient. The most commonly prescribed FDCs belonged to the category of respiratory FDCs in all age groups except in 68 to 77 age group in which cardiovascular FDCs were commonly prescribed. The second most common class of FDCs was anti-infective and alimentary FDCs in younger age groups while cardiovascular and alimentary in the geriatric population. 
FDCs consumption was maximum in heart diseases like hypertension $(32.66 \%)$ diabetes $(28.90 \%)$ followed by lower respiratory tract infections $(28.08 \%)$ and upper respiratory tract infections $(7.52 \%)$ and lastly ischemic heart disease (1.98) and dengue (1.98\%).

Oral dosage form $(77 \%)$ was preferred over other dosage forms. Approximately $80 \%$ of the patients were prescribed with oral dosage forms. This is because the oral dosage form is easy to administer and doesn't need the help of a professional healthcare provider. In our study, the maximum score for rationality assessment was 14 (score of 6 and below was considered irrational whereas a score of 7 and above was considered rational).

Out of 86 rational FDCs, 53(51.46\%) were Drug Controller General of India (DCGI) approved whereas 33 FDCs $(38.37 \%)$ were not approved by DCGI. Out of 103 FDCs, 36 (34.95\%) FDCs were having all the APIs in the WHO Essential Medicine List (EML) whereas 34 (33.01\%) FDCs were having none of their APIs in WHO EML. WHO causality assessment revealed 554 possible, 189 probable, 141 unlikely and 1 unassessible ADR i.e. total 886 ADRs occurred in total 500 patients with a mean of $1.81 \pm 1.9$. The Hartwig severity scale used to assess the severity of the ADRs showed that 627 ADRs were mild in nature $(71 \%)$ and the remaining 259 ADRs were moderate $(29 \%)$ with 0 severe ADRs. The respiratory FDCs contributed to the 511 ADRs $(57.68 \%)$ in 179 patients (52.19\%) contributing to majority of ADRs followed by Cardiovascular FDCs contributing to 157 ADRs (17.72\%) in 70 patients $(20.41 \%)$ and lastly Antiinfective FDCs causing 104 ADRs $(11.74 \%)$ in 43 patients (12.54). 113 ADRs $(12.75 \%)$ were due to other classes of FDCs seen in 53 patients $(15.45 \%)$. Rational FDCs caused 771 ADRs
$(87.02 \%)$ than irrational FDCs $115(12.98 \%)$. Banned FDCs contributed to 76 ADRs $(8.58 \%)$.

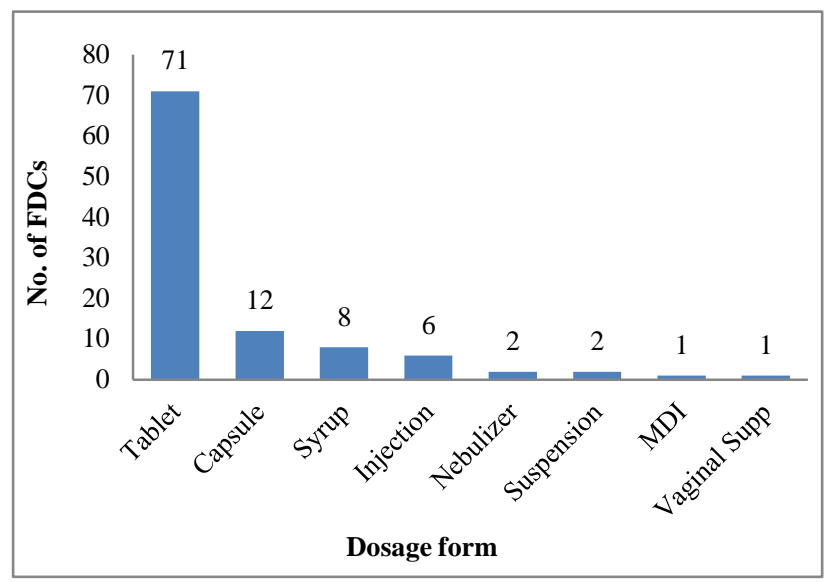

Figure 2: Dosage form distribution.

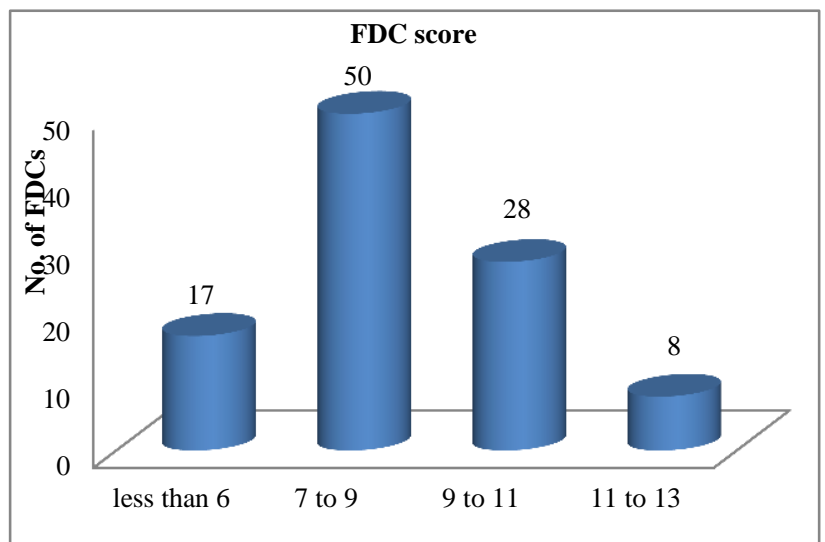

Figure 3: Rationality scoring of FDCs. ${ }^{4}$

Table 1: FDCs associated with the ADRs $(n=422)$.

\begin{tabular}{|c|c|c|}
\hline$\overline{A D R}$ & No of patients & Associated FDC \\
\hline Drowsiness & 172 & $\begin{array}{l}\text { Chlorpheniramine+Codeine; Dextromethorphan+Phenylephrine+Triprolidine; } \\
\text { Dextromethorphan+Phenylephrine+Chlorpheniramine+Guaifenesin; } \\
\text { Paracetamol+Chlorpheniramine+Pseudoephedrine; } \\
\text { Cetrizine+Dextromethoprhan+Phenylephrine; Cetrizine+Phenylephrine; } \\
\text { Levocetrizine+Montelukast ; } \\
\text { Paracetamol+Chlorpheniramine+Dextromethorphan. }\end{array}$ \\
\hline Dry mouth & 108 & \multirow{2}{*}{ Nebulizers like Salbutamol+Ipratropium bromide; Formoterol+Budesonide. } \\
\hline Cough & 59 & \\
\hline $\begin{array}{l}\text { Irregular or } \\
\text { increased heart } \\
\text { rate }\end{array}$ & 81 & $\begin{array}{l}\text { Anticholinergic containing FDCs like; } \\
\text { Salbutamol+Ipratropium bromide; } \\
\text { Dextromethorphan+Phenylephrine+Triprolidine; } \\
\text { Dextromethorphan+Phenylephrine+Chlorpheniramine+Guaifenesin; } \\
\text { Risperidone+Trihexiphenidyl. }\end{array}$ \\
\hline Nausea & 53 & \multirow{2}{*}{ Amoxicillin+Clavulanate; Paracetamol+Tramadol; Cefixime+Clavulanate. } \\
\hline Vomiting & 16 & \\
\hline $\begin{array}{l}\text { Abdominal } \\
\text { discomfort }\end{array}$ & 36 & \multirow{2}{*}{$\begin{array}{l}\text { Tramadol+Paracetamol; Dicyclomine+Mefenamic acid; } \\
\text { Dicyclomine+Paracetamol; Diphenoxylate+Atropine; } \\
\text { Medicines having antispasmodic (Dicyclomine) and anticholinergic properties } \\
\text { (Dicyclomine and Atropine) tend to cause constipation because of reduced } \\
\text { muscle contraction. }\end{array}$} \\
\hline Constipation & 24 & \\
\hline
\end{tabular}




\begin{tabular}{|c|c|c|}
\hline ADR & No of patients & Associated FDC \\
\hline Hypotension & 59 & $\begin{array}{l}\text { Spironolactone+Furosemide; Amlodipine+Hydrochlorothiazide+Telmisartan; } \\
\text { Spironolactone+Torsemide; Metoprolol+Amlodipine; } \\
\text { Telmisartan+Amlodipine; Amlodipine+Atenolol. }\end{array}$ \\
\hline Diarrhea & 36 & $\begin{array}{l}\text { Ofloxacin+Ornidazole; Piperacillin+Tazobactam; Ciprofloxacin+Tinidazole; } \\
\text { Satranidazole+Ofloxacin. }\end{array}$ \\
\hline Anorexia & 24 & $\begin{array}{l}\text { Lamivudine+Nevirapine+Zidovudine; Ritonavir+Lopinavir; } \\
\text { Trimethoprim+Sulfamethoxazole; Lamivudine+Tenofovir+Efavirenz; } \\
\text { Lamivudine+Stavudine; Rifampicin+Isoniazide; Artemether+Lumefantrine. }\end{array}$ \\
\hline Hypokalemia & 23 & $\begin{array}{l}\text { Salbutamol+Ipratropium bromide; Telmisartan+Hydrochlorothiazide; } \\
\text { Losartan+Hydrochlorothiazide; } \\
\text { The risk was higher when the patient was administered with both salbutamol and } \\
\text { thiazides or other potassium increasing antihypertensives. }\end{array}$ \\
\hline $\begin{array}{l}\text { Transient } \\
\text { eosinophilia }\end{array}$ & 12 & $\begin{array}{l}\text { Cefoperazone+Sulbactum; } \\
\text { The reaction is seen within } 24 \text { hours of administration and subsides with } \\
\text { consequent administration. }\end{array}$ \\
\hline $\begin{array}{l}\text { Increased liver } \\
\text { enzymes }\end{array}$ & 9 & Lamivudine+Zidovudine+Nevirapine; Aspirin+Atorvastatin. \\
\hline Pruritus & 5 & Guaifenesin+Terbutalin+Ambroxol; Chlorpheniramine+Codeine+Menthol. \\
\hline Parkinsonism & 1 & Amlodipine+Atenolol. \\
\hline
\end{tabular}

Table 2: List of banned FDCs prescribed in the inpatients.

\begin{tabular}{|c|c|c|c|}
\hline Name of banned FDC & Possible reason for banning & ATC category & $\begin{array}{l}\text { Observed } \\
\text { ADRs }(n=76)\end{array}$ \\
\hline $\begin{array}{l}\text { Dextromethorphan+phenyleph } \\
\text { rine+triprolidine }\end{array}$ & $\begin{array}{l}\text { The risk or severity of adverse effects can be } \\
\text { increased when triprolidine is combined with } \\
\text { dextromethorphan. }{ }^{5} \text { Another reason is there is } \\
\text { insufficient evidence that oral Phenylephrine } \\
\text { is effective for OTC use as a decongestant. }\end{array}$ & Respiratory & 45 \\
\hline $\begin{array}{l}\text { Dextromethorphan+phenyleph } \\
\text { rine+chlorpheniramine+guaife } \\
\text { nesin }\end{array}$ & $\begin{array}{l}\text { Guaifenesin which is an expectorant that helps } \\
\text { to produce more productive cough so that it } \\
\text { will get expelled through coughing reflex, but } \\
\text { antitussive action of dextromethorphan } \\
\text { inhibits the coughing by inhibiting the reflex, } \\
\text { thus combining both will result in nullified } \\
\text { action. }\end{array}$ & Respiratory & 7 \\
\hline Chlorpheniramine + codeine & $\begin{array}{l}\text { Highly abused and lack of therapeutic } \\
\text { justification. }\end{array}$ & Respiratory & 17 \\
\hline Aceclofenac+paracetamol & $\begin{array}{l}\text { The strength of paracetamol as analgesic in } \\
\text { FDC should be } 325 \mathrm{mg} \text { as per DCGI, but the } \\
\text { FDC has usual dose of paracetamol which in } \\
\text { synergism with aceclofenac is enough for } \\
\text { liver failure. }\end{array}$ & Musculoskeletal & 0 \\
\hline $\begin{array}{l}\text { Cetirizine+dextromethorphan } \\
\text { +phenylephrine+menthol }\end{array}$ & $\begin{array}{l}\text { The risk or severity of ADRs is increased } \\
\text { when antihistaminic like cetrizine is combined } \\
\text { with antitussive like dextromethorphan. Also } \\
\text { there is insufficient evidence that oral } \\
\text { phenylephrine is effective for OTC use as a } \\
\text { decongestant. }\end{array}$ & Respiratory & 7 \\
\hline
\end{tabular}

The most common ADRs with the banned FDCs were drowsiness followed by irregular heart rate, though the combination of chlorpheniramine+codeine was also associated with pruritus and itching besides the drowsiness and increased heart rate. The risk of palpitations was high in cardiovascular patients receiving antihypertensive medicines. The majority of FDCs 95 $(92.23 \%)$ were costlier than the sum of the cost of individual APIs and only 8 FDCs $(7.77 \%)$ were cheaper than the sum of the cost of individual APIs. 


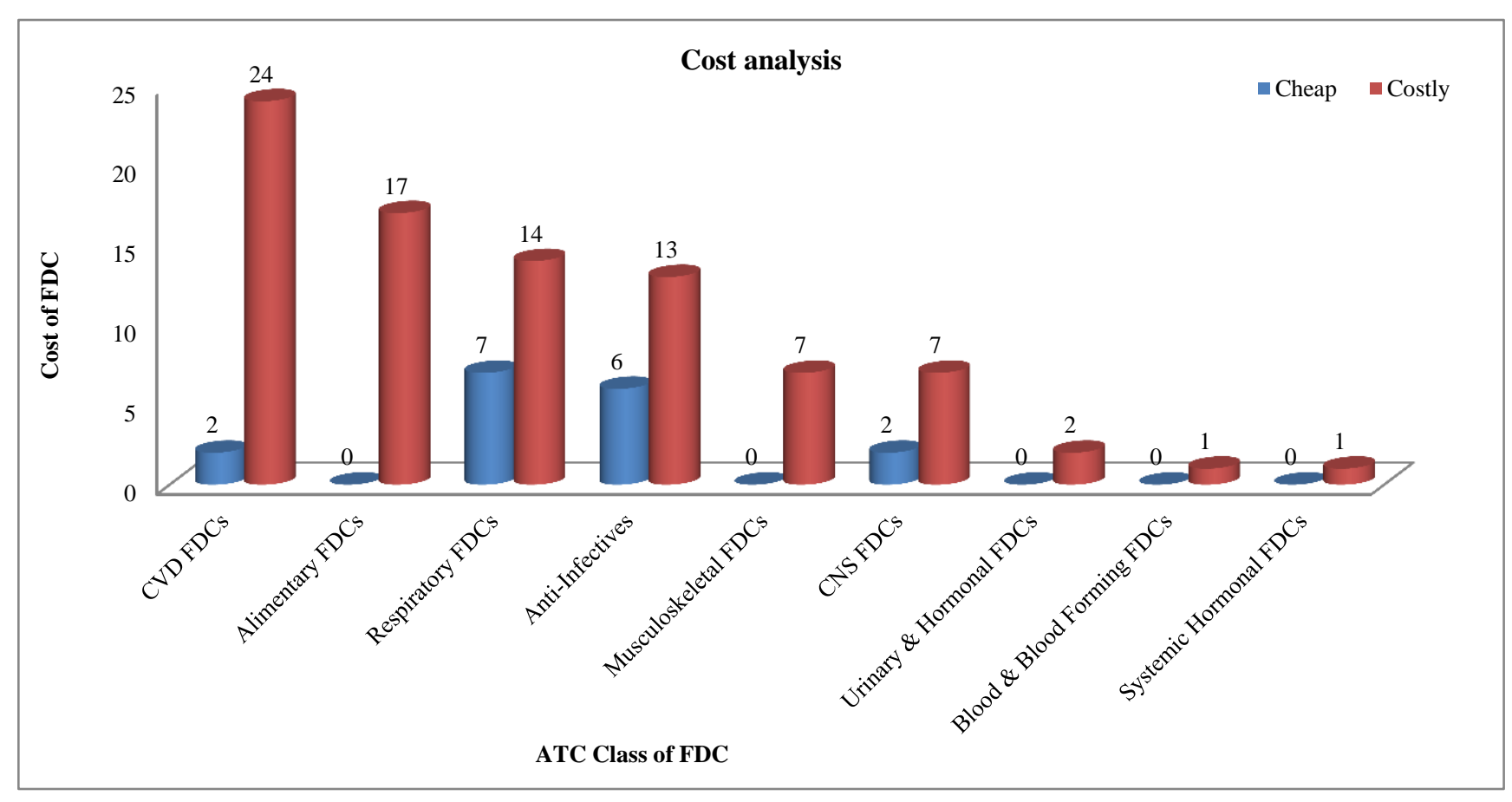

Figure 4: Cost analysis of FDCs compared to the individual API.

\section{DISCUSSION}

The most commonly prescribed FDCs belonged to the category of respiratory FDCs in all age groups except the age group between 68 to 77 years in which cardiovascular FDCs were commonly prescribed. The second most common class of FDCs was anti-infectives and alimentary FDCs in younger age groups while Cardiovascular and Alimentary in the geriatric population. The results were varying between different studies like in the study of Balasubramaniam et al, antibiotics were most commonly prescribed followed by antidiabetic FDCs. ${ }^{12}$ Pradhan et al had multivitamins, Paudel et al had antimicrobials in PHC and SHC, THC had multivitamins, Manjunatha et al had alimentary FDCs most commonly prescribed followed by anti-infectives and blood and blood forming FDCs. ${ }^{13-15}$ Whereas, Dhande et al had analgesics as most commonly prescribed followed by nutritional supplements. ${ }^{16}$ In this study, 34.95\% FDCs had all the APIs in the WHO EML whereas $33.01 \%$ FDCs had none of their APIs in the EML. Yadav et al had most of their FDCs having none of their APIs in WHO EML (35.71\%); showing a little deviation from the present study. ${ }^{17}$

The present study had a majority of rational FDCs $(83.5 \%)$. Similar findings to the study done by Gupta et al showing $75 \%$ of rational FDCs. ${ }^{18}$ On the other hand a study by Pradhan et al showed a majority of irrational FDCs $(70 \%)$ possibly because the study included the nutraceutical supplements which have a wide range of components that may or may not have therapeutic justification. ${ }^{13}$ Along with the study of Upadhyay et al, Nazmi et al also showed fewer rational FDCs than irrational, showing the percentage of $13.31 \%$ and $30 \%$ respectively. The possible reason is that these studies are either prescription based or are done in the outpatient setting where chances of prescribing irrational FDCs are more due to less stringent rules and unawareness about FDCs. ${ }^{1,19}$ Oral dosage form was preferred over parenteral. The finding is also supported by the studies of Pradhan et al, Balat et al and Dhande et al. ${ }^{13,16,20}$

The present study had a majority of possible ADRs $(62.53 \%)$, mild in terms of severity $(71 \%)$. Likewise a study by Gor et al had $80 \%$ of possible ADRs with the majority being mild, as the rechallenge and dechallenge may not have occurred in the patients administering the non-steroidal anti-inflammatory drugs. ${ }^{21}$ Different outcome in terms of causality assessment in the study done by Sudhakar et al showed majority of probable ADRs (85.2\%); because even if it is not possible to actually perform rechallenge and dechallenge because of ethical concern, withdrawal of medicine after the occurrence of ADR and consequent decrease in ADR intensity can validate the probable causality assessment. ${ }^{22}$ Differing in case of causality but similar in case of severity, the study done by Mukherjee et al had $83.03 \%$ probable/likely ADRs with majority ADRs being mild $(83.33 \%)$. Because the study was done in case of antiretroviral medicines where there is no other option but to withdraw the drug when ADR occurs, and continue it upon the alleviation of ADR and so the majority of the ADRs fall under certain or probable causality. ${ }^{23}$ Dual drug combinations were prominent in the present study constituting 85 FDCs, and rest were multidrug combinations; similar to the study done by Shende et al. ${ }^{24}$ Also, $92.23 \%$ of FDCs were costlier than the sum of the cost of individual API. This was similar to the study by 
Nazmi et al stating $70 \%$ of FDCs were costlier. ${ }^{19}$ However, FDCs were found to be cheaper in the study by Tahir et al. ${ }^{25}$

\section{CONCLUSION}

The present study highlights the greater use of FDCs in the tertiary care teaching hospital. Even though rational FDCs were found to be mostly prescribed in the study, the focus was on the banned FDCs which are still prescribed. Also, a similar study in the private setting has to be conducted to understand the pattern of FDCs used in a private setting.

\section{ACKNOWLEDGEMENTS}

This study would not have succeeded without the guidance and help of several individuals who have contributed and extended their valuable assistance for the preparation and completion of this study in one way or another. We are thankful to our faculty, healthcare team and patients and last but not least every other person who has directly or indirectly contributed to our study.

Funding: No funding sources

Conflict of interest: None declared

Ethical approval: The study was approved by the Institutional Ethics Committee

\section{REFERENCES}

1. Upadhyay D, Singh A, Joshi HA, et.al. Study of prescription patterns of fixed dose combinations prescribed by medical interns. Int $\mathrm{J}$ Biomed Res. 2016;7:624-8.

2. Gupta KY, Suganthi SR. Fixed dose drug combinations: issues and challenges in India. Indian $\mathbf{J}$ Pharmacol. 2016;48(4):347-9.

3. Mohanty BK, Aswini M, Hasamnis A, Patil SS, Mutry KSN, Jena SK, et al. Prescription pattern in the department of medicine of a tertiary care hospital in south India. J Clin Diagnos Res. 2010;3:2047-51.

4. Panda J, Tiwari P, Uppal R. Evaluation of rationality of some FDCs: Focus on anti-hypertensive drugs. Int J Pharma Sci. 2006;68(5):649-53.

5. Drugs.com. Drug Interaction Report. Available at: https://www.drugs.com/interactions-check.php? drug_list=844-0,1964-0,2257-0. Accessed on 3 October 2019.

6. Hendeles L, Hatton RC. Over-the-Counter Oral Phenylephrine: A Placebo for Nasal Congestion. J Allergy Clin Immunol. 2015;3(5):279-80.

7. Rubin BK. Mucolytics, expectorants, and mucokinetic medications. J Respiratory Care. 2007;52(7):859-64.

8. Mattoo SK, Basu D, Sharma A, Balaji M, Malhotra A. Abuse of codeine-containing cough syrups: a report from India. Society Study Addiction J. 1997;92(12):1783-7.
9. Thehindubusinessline.com. (2016). Who banned my cough syrup? And why? Available at: https://www. thehindubusinessline.com/specials/pulse/whobanned-my-cough-syrup-and-why/article 8371387.ece Accessed on 3 October 2019.

10. Pharmabiz.com. (2014). Lowering of paracetamol to $325 \mathrm{mg}$ applicable to FDC with other analgesic/antiinflammatory drugs only: DCGI. Retrieved from http://www.pharmabiz.com/NewsDetails.aspx?aid=7 9911\&sid=1. Accessed on 3 October 2019.

11. NEXT DT. (2019). Top 10 commonly used medication now banned in India. Available at: https://www.dtnext.in/Preview/Wellbeing/2016/03/17 133641/Top-10-commonly-used-medication-nowbanned-in-India.vpf. Accessed on 3 October 2019.

12. Balsubramaniam R, Hariharan D, Pamulapati TV, Devrajan V, Shanmugam S, Manjuladevi AS. A study on evaluation of rationality of fixed dose combinations. Am J Pharm Res. 2013;3(5):538-47.

13. Pradhan S, Panda A, Behera JP. An evaluation of prevalence and prescribing patterns of rational and irrational fixed dose combinations (FDCs): a hospital based study. Int J Med Sci Public Health. 2017;6(1):58-62.

14. Poudel A, Izham M, Mishra P, Palaian S. Assessment of utilization pattern of fixed dose drug combinations in primary, secondary and tertiary healthcare centers in Nepal: a cross-sectional study. BMC Pharmacol Toxicol. 2017;18(69).

15. Manjunatha $\mathrm{CH}$, Rohith V, Maheshwari R, Topno I. Prescription Pattern of fixed dose drug combinations in obstetrics and gynecology department of a tertiary care hospital in Puducherry, India: an observational study. Int J Basic Clin Pharmacol. 2018;7(11).

16. Dhande P, Patel H, Gupta A. Prescribing trend of fixed dose combinations (FDCs) in a tertiary care teaching hospital in western India. Euro J Biomed Pharma Sci. 2015;2(5):429-39.

17. Yadav AK, Jeenger J, Panwar D. Evaluation of rationality of fixed dose combinations prescribed in psychiatric patients. National J Physiol Pharma Pharmacol. 2016;6(2):150-4.

18. Gupta R, Malhotra A, Malhotra P. Assessment of rational use of fixed dose combinations in hypertension in a tertiary care teaching hospital in north India. Int J Adv Med. 2018;5(5):1263-67.

19. Nazmi A, Umme A. Prescribing trends of fixed dose combination using WHO guidelines. J Biological Chem. 2015;32(2):471-7.

20. Balat JD, Gandhi AM, Patel PP, Dikshit RK. A study of use of fixed dose combinations in Ahmedabad, India. Indian J Pharmacol. 2014;46(5):503-9.

21. Gor AP, Shah BK. Evaluation of prescribing pattern and adverse effects of fixed dose combination of nonsteroidal anti-inflammatory drugs. Int $\mathrm{J}$ Basic Clin Pharmacol. 2016;5(3):1029-33.

22. Sudhakar K, Deepa Latha C, Baloju D, Malahat AR, Vijayalakshmi G. Study to evaluate use of irrational fixed dose combinations. Int J Current Pharma Res. 2017;9(5):64-6. 
23. Mukherjee S, Era N, Saha B, Tripathi SK. Adverse drug reaction monitoring in patients on antiretroviral therapy in a tertiary care hospital in eastern India. Indian J Pharmacol. 2017;49(3):223-8.

24. Shende TR, Siddiqui RA, Mahajan HM. A drug utilization study of fixed dose combinations used in hypertension in rural tertiary healthcare centre of central India. Int J Current Res Rev. 2016;8(12):30-4.

25. Tahir A, Gulati K, Lalit M, Shinoy S, Patil N. Evaluation of prescribing pattern of fixed dose combination of drugs in outpatients of cardiology in tertiary care hospital. World J Pharm Pharma Sci. 2014;3(11):623-2.

Cite this article as: Joshi N, Falke A, Saji S, Diwan A, Raut A. Evaluation of prescribing pattern and rationality of fixed dose combinations in patients of general medicine department. Int J Basic Clin Pharmacol 2020;9:122-8. 